\title{
Catalytic Enantioselective Diels Alder Reaction: Application in the Synthesis of Antiviral Agents ${ }^{\dagger}$
}

\author{
Alessandro Grillo $^{1}$ a and Bruno Mattia Bizzarri $^{2, *(D)}$ \\ 1 Promidis (IRBM Group), Via Olgettina 60, Torre San Michele 1, Ospedale San Raffaele, 20132 Milano, Italy; \\ grillo.alessandro@ymail.com \\ 2 Biological and Ecological Sciences Department (DEB), University of Tuscia, 01100 Viterbo, Italy \\ * Correspondence: bm.bizzarri@unitus.it \\ + Paper is dedicated to Silvana Grande and Professor Arun K. Ghosh on the occasion of their 64th birthday.
}

check for updates

Citation: Grillo, A.; Bizzarri, B.M Catalytic Enantioselective Diels Alder Reaction: Application in the Synthesis of Antiviral Agents. Catalysts 2022, 12, 150. https:// doi.org/10.3390/catal12020150

Academic Editors: Pierre Vogel and Carlos Vila

Received: 23 December 2021

Accepted: 21 January 2022

Published: 25 January 2022

Publisher's Note: MDPI stays neutral with regard to jurisdictional claims in published maps and institutional affiliations.

Copyright: (C) 2022 by the authors. Licensee MDPI, Basel, Switzerland. This article is an open access article distributed under the terms and conditions of the Creative Commons Attribution (CC BY) license (https:// creativecommons.org/licenses/by/ $4.0 /)$.

\begin{abstract}
The Diels-Alder reaction (DAR) is one of the most effective and reliable strategies for the construction of six-membered carbocyclic and heterocyclic rings, and it is widely used in the synthesis of organic molecules and drugs. Due to the high regio- and stereo-selectivity and its versatility, DARs have represented a powerful tool for organic chemistry for many years. In addition, the asymmetric DAR has become a fundamental synthetic approach in the preparation of optically active six-membered rings and natural compounds. The COVID-19-related pandemic requires continuous research; DAR represents an useful method to obtain optically active intermediates for the synthesis of antiviral agents under different catalytic conditions. We would like to highlight an intriguing synthetic procedure applied to the development of novel synthetic protocols that are potentially useful against a large panel of viruses and other unmet diseases.
\end{abstract}

Keywords: Diels-Alder reaction (DAR); enantioselective catalysis; six-membered ring; antiviral agents; SARS-CoV-2; COVID-19

\section{Introduction}

The Diels-Alder reaction (DAR) is one of the most effective and reliable strategies for the construction of six-membered carbocyclic and heterocyclic rings, and it is widely used in the synthesis of molecules endowing biologically activity.

Since the seminal work of Otto Diels and Kurt Alder in 1928, the advances and development of the reaction have emerged at an impressive rate, and enormous advances in this area, besides new contributions, are continuously been reported [1].

With recent and continuous outbreaks of SARS-CoV-2, responsible for the COVID-19 pandemic, it became obvious that the research in the antiviral field needed to be developed and encouraged. This review describes a variety of DARs aimed at obtaining optically active intermediates that are useful for the synthesis of antiviral agents exploiting several catalytic conditions. The DAR can be defined as a [4+2] cycloaddition in which a conjugate diene reacts with a dienophile to form an adduct endowing six membered ring with the formation of two new $\sigma$ bonds, starting from two $\pi$ bonds $[2,3]$ (Scheme 1).

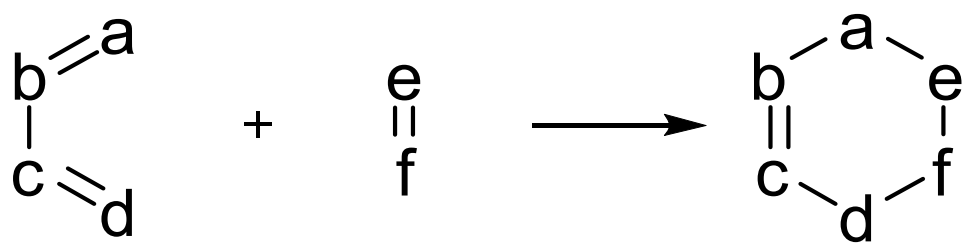

Scheme 1. General formula of DAR. 
The rate of DAR is determined by the degree of interaction between the highest occupied molecular orbital (HOMO) of one component and the lowest unoccupied molecular orbital (LUMO) of the other. In a classical DAR, the interaction is between the HOMO of the diene and the LUMO of dienophile (electron-withdrawing groups on dienophile and electron-donating ones on the diene accelerate the reaction by reducing the energy gap between these orbitals). In DARs with inverse electron demand, the interaction which controls the reaction occurs in an opposite fashion. When the diene and dienophile are part of the same molecule, it is usually referred to as an intramolecular DAR cycloaddition [4]. On the other hand, when the diene or the dienophile in DAR contains a heteroatom, we can talk about hetero-DA reaction (HDAR) [4]. DARs are often slow and require either thermal activation or chemical promoters for the in situ generation of reactive dienophiles [5]. Even if this kind of reaction proceeds easily at either ambient or high temperature, the yield can be improved, working at a higher pressure, and the reaction can be accelerated by catalysis. In this latter case, the presence of a selected catalyst can also control the stereoselectivity [6], thus allowing us to obtain enantio-enriched DAR adducts. The purpose of this manuscript is to furnish an overview of the chiral catalysts developed in recent years, highlighting the useful role of DAR in the synthesis of antiviral agents, endowing optical activity. Recently Quadrelli et al. dedicated a chapter of a book to the cycloaddition reactions used for the synthesis of antiviral compounds [7], and a recent review described the biocatalytic routes applied to antiviral agents [8]. Taking into consideration our experience in the antiviral field [9-18] and in the application of DAR to the synthesis of antiviral agents [15,18] we were interested to investigate this topic in more detail. We show some examples in which the catalytic DARs furnish useful optically active intermediates for the synthesis of selected bioactive compounds after a brief introduction of enantioselective DAR. An overview of the catalysts used so far to obtain interesting intermediate with high enantiomeric excess, which hopefully could contribute to the treatment of COVID-19, is also accomplished.

\section{Discussion}

\subsection{Asymmetric DAR}

There are two strategies that are widely used to achieve DAR adducts in high enantioselective fashion, encompassing the use of auxiliary-based reactions [19] or the use of chiral catalysis. Even if the asymmetric DAR using a chiral auxiliary was developed more than 35 years ago [19] and it is still largely used, there are some intrinsic limitations related to the introduction and the removal of auxiliaries used in equimolar amounts. The discovery of Lewis acid (LA) as a catalyst for DAR prompted many research groups to investigate chiral LA that is able to afford DAR adducts endowing optical activity [20]. Moreover, bases can catalyze DAR in an enantioselective manner. Chiral LA or bases result in being very interesting, especially because a catalytic amount of chiral component can produce a huge amount of desired compound. In this manuscript we present different strategies useful to obtain, in selected examples, the same chiral intermediate, working also on the gram scale. The dienophiles reported in this review that act in the DAR are summarized into two main groups, those which bind to the LA at one point and those which bind at two points. Unsaturated aldehydes and esters are here reported as an example for the first category, while 3-alkenoyl-1,3-oxazolidin-2-ones, a good bidentate ligand, is representative for the second one.

\subsection{Asymmetric DAR (Unsaturated Aldehydes or Ester as Dienophiles)}

Koga and coworkers in 1979 were the pioneers in the use of chiral LA catalyzing DAR [21]. The menthoxyaluminum dichloride (A, Scheme 2) prepared from $\mathrm{EtAlCl}_{2}$ and menthol promoted the DAR between cyclopentadiene $\mathbf{1}$ and methacrolein $\mathbf{2}$ in $72 \%$ ee. Chiral aluminum catalyst $\mathbf{B}$ (Scheme 2), prepared from $\mathrm{Et}_{2} \mathrm{AlCl}$ and a biaryl ligand, is reported to be an effective LA catalyst for the same reaction affording the adduct in $97.7 \%$ ee $[22,23]$. Similarly, Kobayashi and Mukaiyama developed a zwitterionic proline-based LA 
(C, Scheme 2) by mixing aminoalcohol and $\mathrm{BBr}_{3}$ and, thus, obtaining high enantioselectivity $(97 \%$ ee) [24].
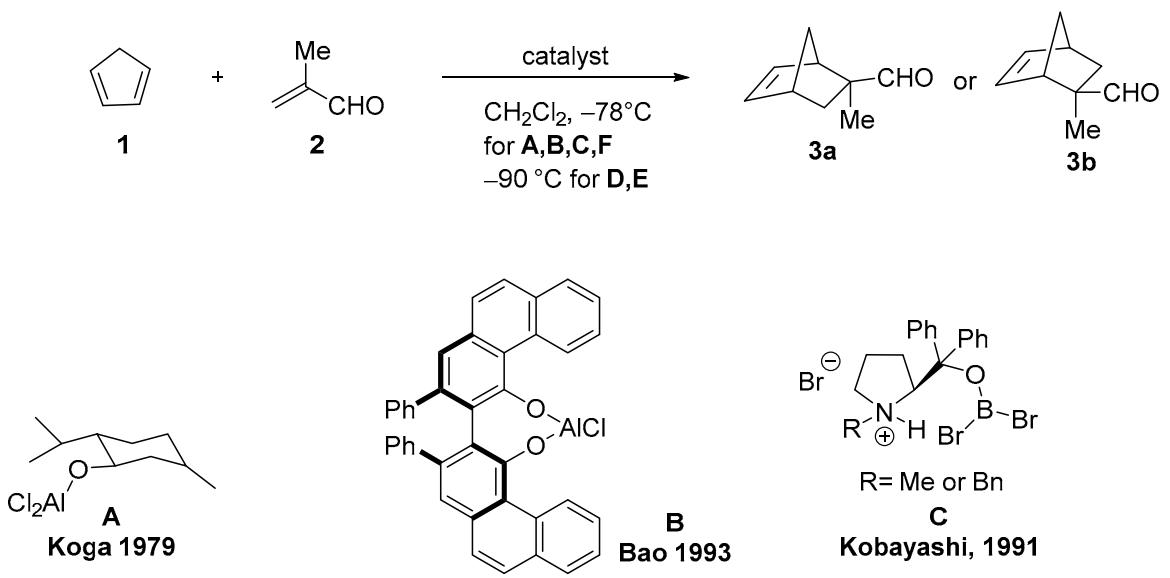

3a, $72 \%$ ee, $69 \%$, endo:exo $=2: 98$

3b, $97.7 \%$ ee, $100 \%$, endo:exo $=>3: 97$

3b, $97 \%$ ee, $84 \%$, endo:exo=>1:99

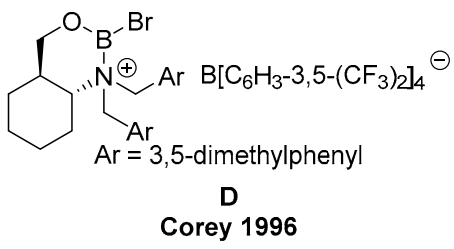

3a, $87 \%$ ee, $98 \%$, endo:exo $=11: 89$

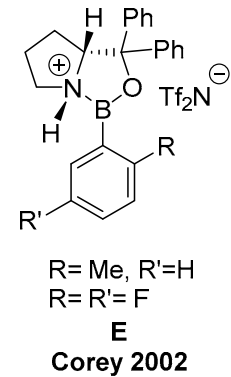

3a, $96 \%$ ee, $97 \%$, endo:exo=>9:91

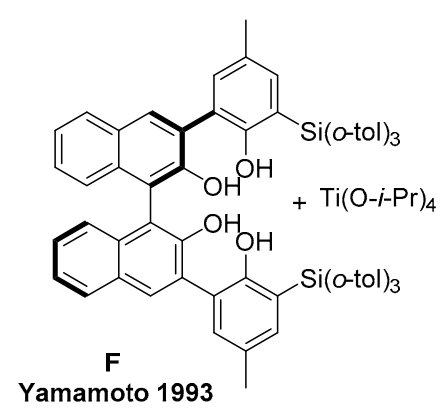

3b, $94 \%$ ee, $75 \%$, endo:exo=>1:99

Scheme 2. Synthesis of bicyclic aldheyde $\mathbf{3 a}$ or $\mathbf{3 b}$ from cyclopentadiene $\mathbf{1}$ and methacrolein $\mathbf{2}$ in presence of chiral catalyst $\mathbf{A}-\mathbf{F}$.

The attachment of higher coordination chiral ligand to a metal normally reduces the Lewis acidity, since additional electron density generally is transferred from ligand to metal. Starting from this consideration, Corey reported a new class of super-reactive chiral LA catalysts [25]. The super-reactive cationic catalyst oxazaborinane (catalyst D, Scheme 2) allowed the reaction between the $\alpha$ and $\beta$ unsaturated aldehydes not only with reactive cyclopentadiene, but also with 1,3-butadiene and 1,3-cyclohexadiene at a lower temperature $\left(-94{ }^{\circ} \mathrm{C}\right)$, in short reaction times and with high exo and enantioselectivity. Triflic acid-activated chiral oxazaborolidine developed later (catalyst E, Scheme 2) furnished very good yields and enantioselectivity at impressive rate [26]. Notably, this catalyst has shown optimal results, even with unreactive dienes, such as 1,3-butadiene and 1,3cyclohexadiene, and it was demonstrated to be useful in DARs, employing a lager variety of dienophiles [27]. Therefore, Corey showed that the coordination of chiral ligands to LA metal derivatives is a useful strategy for enantioselective electrophilic catalysis and generally leads to a lower level of catalytic activity than that of the original uncomplexed compound. Activation by further attachment of a proton or strong LA to the complex provides a way to overcome the deactivating effect of a chiral ligand. He described the further enhancement of catalytic activity by the placement of a double fluorine substituents in the chiral ligand $\mathbf{E}$. This approach has led to a new second-generation family of chiral oxazaborolidinium cationic species that can be used to effect many DARs in $>95 \%$ yield and $>95 \%$ ee, using catalyst loadings at the 1-2 mol\% level [28]. Yamamoto et al. reported a chiral helical titanium catalyst (F, Scheme 2) prepared from a binaphthol-derived chiral tetraol and titanium tetraisopropoxide with azeotropic removal of 2-propanol. This is one of the few catalysts that promote the DAR of unsubstituted aldehydes, such as acrolein, 
with high enantioselectivity. Acrolein reacts not only with cyclopentadiene but also 1,3cyclohexadiene and 1-methoxy-1,3-cyclohexadiene to afford cycloadducts in 96\%,81\% and $98 \%$ ee, respectively [29].

None of the previously described LAs catalyzed asymmetric DARs of diene 4 (Scheme 3), because of its lability under acidic conditions and subsequent polymerization. This evidence prompted Yamatsugu and coworkers to develop a conceptually distinct catalytic asymmetric DA-type reaction that was not dependent on acid catalysis. They speculated that metal alkoxides (or phenoxides) might activate the siloxy diene 4 through the formation of a hypervalent silicate or transmetalation (HOMO-raising mechanism). The catalyst derived from F2-FujiCAPO and $\mathrm{Ba}(\mathrm{Oi}-\mathrm{Pr})_{2}(\mathrm{G}$, Scheme 3$)$ was the most effective in terms of reactivity, enantioselectivity and diastereoselectivity, affording DA adducts $\mathbf{6 , \mathbf { 6 } ^ { \prime }}$ with high enantioselectivity ( $96 \%$ ee) in the presence of CsF as an additive [30].
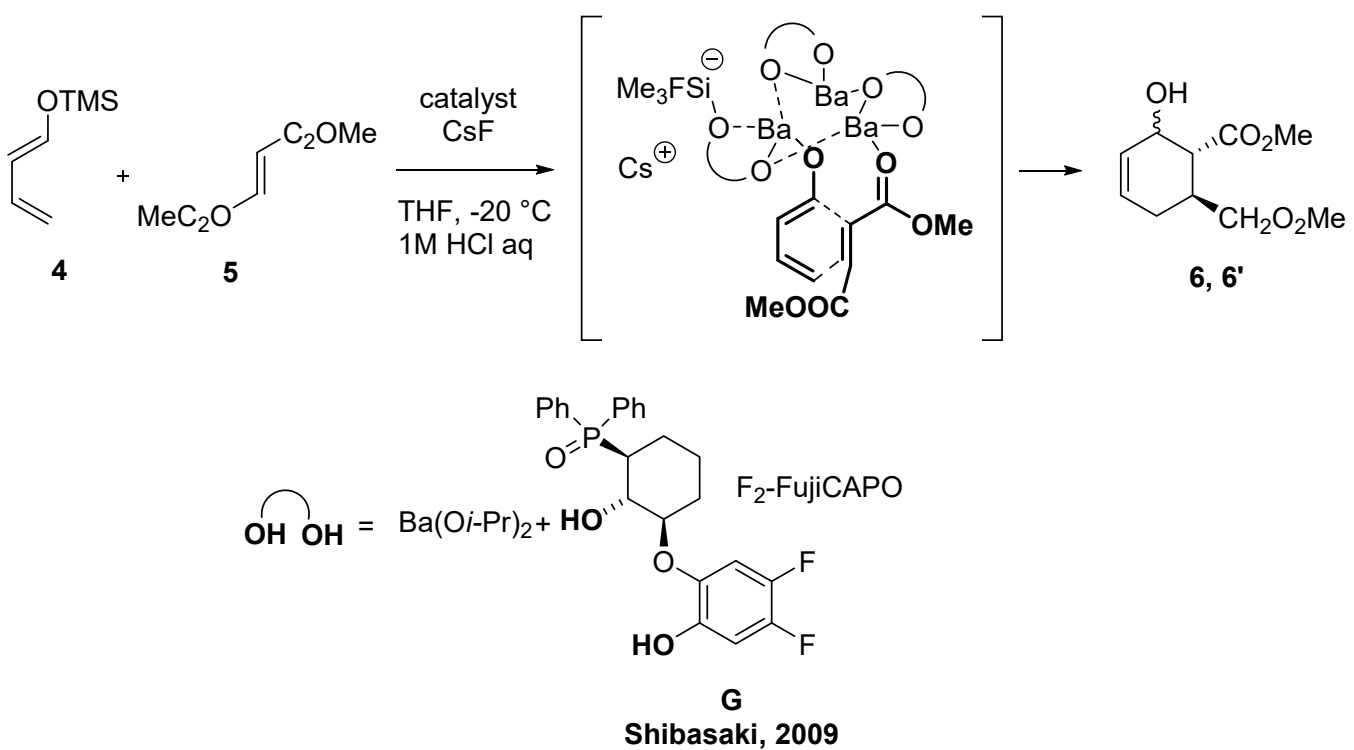

Scheme 3. DAR in presence of chiral catalyst G.

Noticeably, other types of aldehydes activation, including double-point binding, have been previously reported and commonly applied [31-33].

\subsection{Asymmetric DAR (3-Alkenoyl-1,3-Oxazolidin-2-Ones as Diene)}

Since the first successful application of a chiral LA to the DAR between dienophile 7 and cyclopentadiene $\mathbf{1}$ (Scheme 4) that was achieved from Narasaka with Ti(IV) catalyst (TADDOL-based, H, Scheme 4) and promoted DA in over 90\% ee [34], many research groups have been widely investigated this reaction. These latter ones allowed for the discovery of many complexes derived from of metals (Fe(III), $\mathrm{Mg}$ (II), Ti(IV), $\mathrm{Yb}$ (III), $\mathrm{Zr}$-(IV), $\mathrm{Al}(\mathrm{III}), \mathrm{Ni}(\mathrm{II})$ and $\mathrm{Cu}(\mathrm{II}))$ and chiral ligands able to afford the DA adduct counterpart with excellent ee. Corey and co-workers reported catalysts derived from bis-(oxazoline) (box) complexes of $\mathrm{Fe}(\mathrm{III})$ (I, Scheme 4), speculating that the reaction between $\mathbf{7}$ and $\mathbf{1}$, using $10 \mathrm{~mol} \%$, proceeded with 90:10 enantioselectivity to give the endo adduct preferentially (endo:exo ratio 97:3) [35]. 


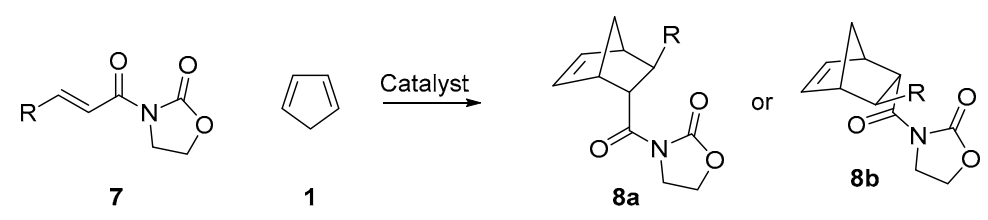

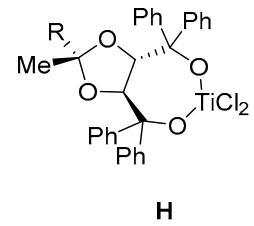

Narasaka 1989

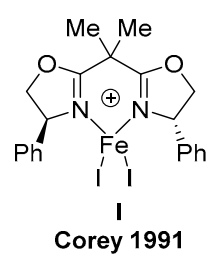

Corey 1991
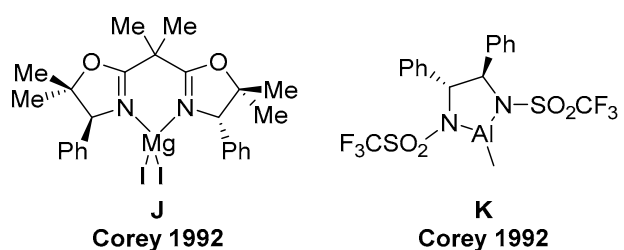
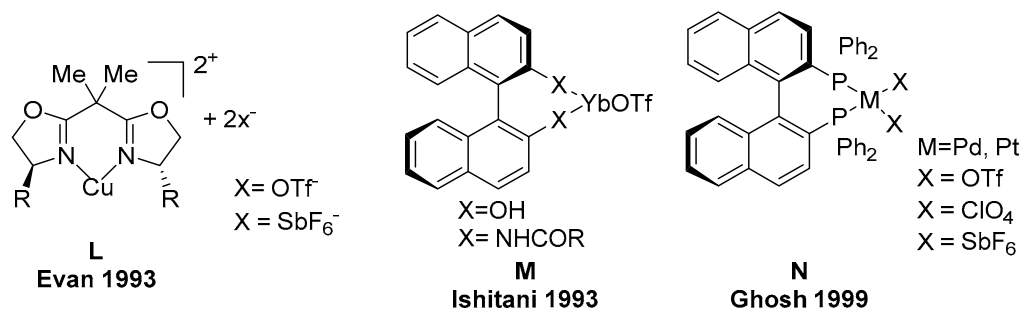

Scheme 4. Synthesis of bicyclic adducts $\mathbf{8 a}$ or $\mathbf{8 b}$, from cyclopentadiene $\mathbf{1}$ and dienophile $\mathbf{7}$ in presence of chiral catalysts $\mathbf{H}-\mathbf{N}$.

Similarly, the treatment of bis-(oxazoline) with $\mathrm{MgI}_{2}$ and $\mathrm{I}_{2}$ (co-catalyst for $\mathrm{I}^{-}$removal) (J, Scheme 4) was used as a catalyst in the same reaction to give the DA product in $82 \%$ yield with 95.3:4.7 enantioselectivity and 97:3 endo:exo selectivity [36]. Other significate contributions from Corey's laboratory described the use of aluminum (III) complex (K, Scheme 4) for enantioselective DAR of imides 7 with ee $=96 \%$ [37].

Evans and colleagues indicated that $[\mathrm{Cu}(\mathrm{box})]-(\mathrm{OTf})_{2}(\mathrm{~L}$, Scheme 4$)$ and related complexes are excellent catalysts for this reaction, highlighting also that the importance of catalyst counterions in modulating Lewis acidity is significant. Cationic $[\mathrm{Cu}(\mathrm{box})]\left(\mathrm{SbF}_{6}\right)_{2}$ complexes exhibit both 20 -fold greater reactivity and superior enantioselection than their triflate counterparts $[38,39]$.

Ishitani found that the chiral BINOL-Yb(III) catalyst $(\mathrm{X}=\mathrm{OH})(\mathbf{M}$, Scheme 4) effectively catalyzes the reaction of $\mathbf{7}\left(\mathrm{R}=\mathrm{H}\right.$, alkyl) with cyclopentadiene at $0{ }^{\circ} \mathrm{C}$ with excellent levels of stereocontrol [40].

Ghosh documented examples of this reaction showing the impact of Platinum and palladium chiral bisphosphine complexes (N, Scheme 4) and their counterion effects in DAR, furnishing a methodology able to afford DA adduct with excellent endo/exo selectivity, as well as endo enantioselectivity (up to $99 \%$ ee) [41].

\subsection{Base Catalyzed Asymmetric DAR (Organocatalysis)}

The first who documented the highly enantioselective organocatalytic DAR reaction were MacMillan and coworkers in a JACS 2000 [42]. Even if some milestones were achieved in the organometallic asymmetric catalysts which employ organic molecules and were documented, only one example of enantioselective DAR was reported with moderate yield [43]. Specifically, MacMillan hypothesized that the LUMO activation that was obtained by using the LA could be emulated with a carbogenic system (iminium ions from $\alpha-\beta$ unsaturated aldehyde and amine) that exists in a rapid equilibrium between an electron deficient and a relatively electron rich state, as shown in Scheme 5A. Accordingly, this observation allowed them to conclude that chiral amines could be employed as enantioselective catalyst in all transformations that required metal salts. MacMillan and coworkers speculated that 
condensation of cinnamaldehyde 9 with an enantiopure amine would lead to the formation of an iminium ion $\mathbf{1 0}$ that is sufficiently activated to engage a diene reaction partner. Accordingly, DAR would lead to iminium ion 11, which, upon hydrolysis, would provide the enantio-enriched cycloaddition product 12, while reconstituting the chiral amine catalyst. The best results in terms of ee was enriched with catalyst $\mathbf{O}$ (Scheme 5B).
Substrate
Catalyst
LUMO-activation

A

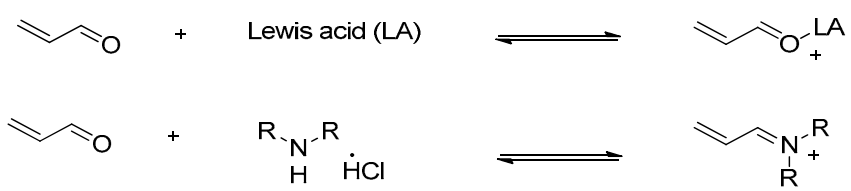

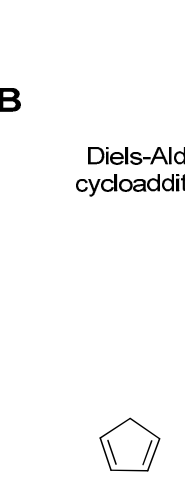

Diene

1

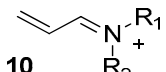

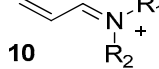

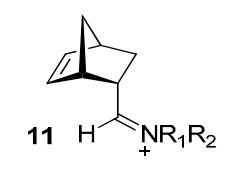

Catalyst $=\mathrm{R}_{1}-\mathrm{N}^{-\mathrm{R}_{2}}$

$\mathrm{H} \dot{\mathrm{HCl}}$

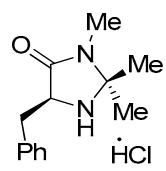

O

MacMillan 2000

Scheme 5. (A) LUMO activation obtained using the LA compared with a carbogenic system (iminium ions from alfa, beta unsaturated aldehyde and amine). (B) Organocatalyzed DA reaction between cinnamaldehyde $\mathbf{9}$ and cyclopentadiene $\mathbf{1}$.

One example employing a MacMillan catalyst has been reported for the organocatalytic asymmetric version of DAR of 1,2-dihydropyridines with cinnamaldehyde affording chiral isoquinuclidines [44]. Nevertheless, this reaction afforded low chemical yield (26\%), but excellent enantioselectivity ( $99 \%$ ee). In this scenario, Fujita and coworkers later developed a novel organocatalyst that afforded chiral isoquinuclidines with better chemical yield and similar enantioselectivity. In designing the planned catalyst, they started from previously developed phosphinooxazolidine (POZ) ligand A (13, Scheme 6), which, in a complex with $\mathrm{Pd}$, worked to give high enantioselectivity $[45,46]$. Starting from previous encouraging results, they designed a series of oxazolidines, 2,4-substituted 5,5-diphenyloxazolidines (Scheme 6), as a novel organocatalyst for the DAR of 1,2-dihydropyridines. The oxazolidine catalyst was easily prepared by the reaction of an amino alcohols 14 with a carbonyl compound affording 15, which, after the reaction of $\mathrm{CF}_{3} \mathrm{COOH}$, allowed for the isolation of the catalyst (P, Scheme 6). 


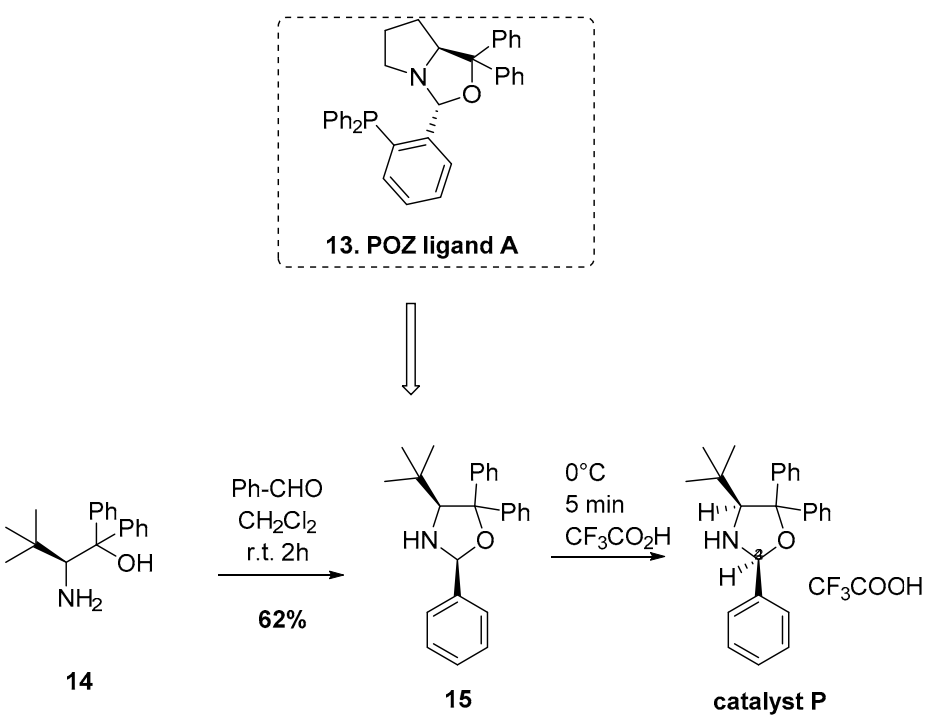

Scheme 6. Synthesis of Catalyst $\mathbf{P}$.

\subsection{Chiral DAR Applied to the Antiviral Agents}

There have been reviews on the applications of this "grand old synthesis", as designated by Corey [47], to the synthesis of elaborated targets [48], and its application to the total synthesis [49]. There are also some examples showing its use in industrial processes on a large-scale application ( $>1 \mathrm{~kg}$ ) [50]. Herein we focus the attention on the DAR applied to the synthesis of the antiviral agents and specifically on the catalysis applied to asymmetric DAR that could be performed by using a directly chiral catalyst or a chiral auxiliary-based reaction catalyzed by classical LA. Antiviral drugs can target the six steps of virus replication: (1) attachment, (2) invasion, (3) uncoating, (4) replication, (5) assembly and (6) release (Figure 1). We have collected some examples in which the DAR was the key step for the synthesis of approved drugs, clinical candidate and natural compound catalogued for mechanism of action.

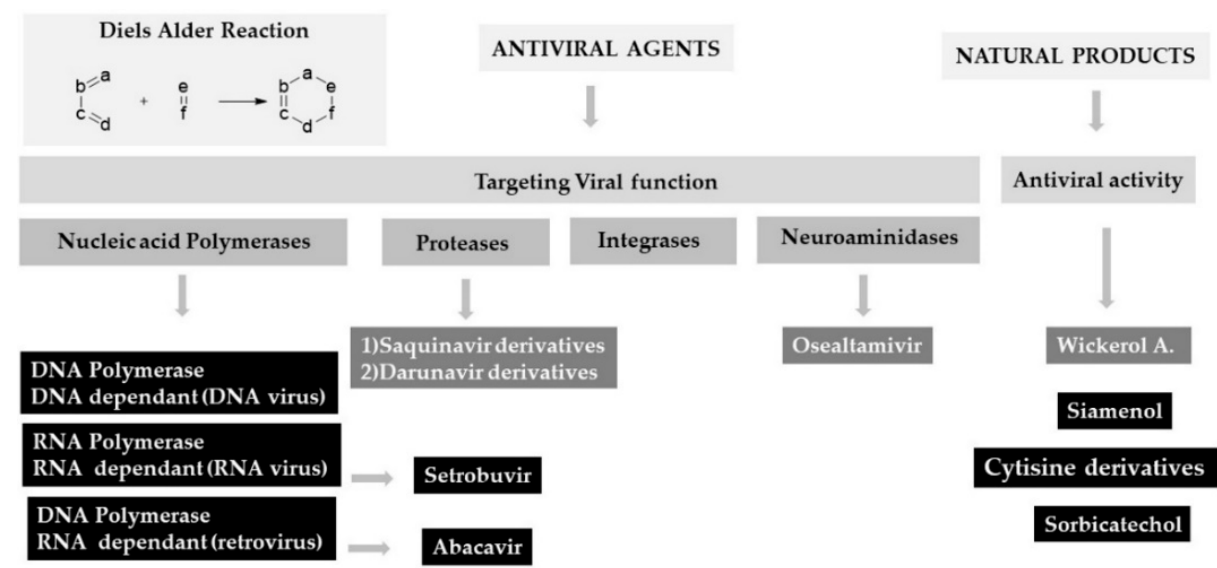

Figure 1. Antiviral agents and natural compounds endowing antiviral activity synthesized by means of DAR.

For example, Abacavir is a reverse transcriptase inhibitor that was launched in 1999 by GSK for the oral treatment of HIV. Its synthesis started from racemic Vince's lactam [51] obtained by means of DAR between cyclopentadiene and methanesulfonyl cyanide performed at the ton scale by Lonza [52]. Setrobuvir, which inhibits the hepatitis $C$ enzyme NS5B, an RNA polymerase, is an experimental drug candidate for treatment of hepatitis C, discovered at Anadys Pharmaceuticals [53,54] and acquired by Roche in 2011; it concluded 
its development in 2015, and the exo-cyclopentadiene-maleic anhydride adduct is used as the starting material.

We are going to describe more in details the processes that envisaged the catalytic asymmetric DAR. At the best of our knowledge, there are not a lot of examples but some of them belonging to the HIV protease inhibitors (Saquinavir's, Darunavir's derivatives), to the neuroaminidase inhibitors (Oseltamivir) and to natural compounds (wickerol A) are very intriguing and clearly help us to show the power of the application of this reaction, that hopefully could push the medicinal chemists to a potential use in drug discovery and in the development of alternative, more convenient synthesis for other approved antivirals agents, thus highlighting the power of this reaction for the rapid generation of molecular complexity.

\subsubsection{Synthesis of Saquinavir Derivatives}

Saquinavir, discovered by Hoffman-La Roche in 1988 and approved by the FDA in 1995, is the first HIV protease inhibitor (PI) for the treatment of AIDS. As reviewed from Ghosh et al., several approaches for its synthesis have been developed [55]. However, the reported synthesis does not allow easy substitution of the carbocyclic ring, which represents a crucial region that could potentially lead to enhanced potency and better pharmacokinetic properties of inhibitors. Herein we present an approach published from Cracket and collaborators in 2004 [56]. They developed a versatile chiral DA route based on chiral auxiliary to a range of carbocyclic mimetics of scissile Phe-Pro. As described in Scheme 7, the chiral dienophile 18, which was obtained by coupling aldehyde $\mathbf{1 6}$ and phosphonate 17 [57] under Masamune-Roush conditions [58], reacts with the 2-(trimethylsilyloxy)1,3-butadiene 19 under LA catalysis $\left(\mathrm{Et}_{2} \mathrm{AlCl}\right)$, affording a 4:1 mixture of diastereomeric trans-diketones $\mathbf{2 0}$ in $\mathbf{8 3} \%$ yield. The required trans isomer, easily separable from the cis, was subjected to reaction by means of $\mathrm{LiOH} / \mathrm{H}_{2} \mathrm{O}_{2}$ and then affording the required tertbutylamide 21 via the $N$-hydroxysuccinimide ester. The equatorial alcohol 22 was obtained by using L-selectride in excellent yields and selectivity. It also could be readily converted to a range of ethers by treatment with $\mathrm{NaH}$ in $\mathrm{DMF}$ at $0{ }^{\circ} \mathrm{C}$ and the corresponding alkyl halide. The equatorial alcohol 22 could also be converted to the saturated carbocycle 23 by transformation to the mesylate, elimination and reduction. Further transformations of 22 and 23, in particular, the removal of N-Boc and acetonide-protecting groups in presence ofdichloromethane/TFA containing a few drops of $\mathrm{H}_{2} \mathrm{O}$ gave amines 24 suitable for further elaboration of HIV protease inhibitors.

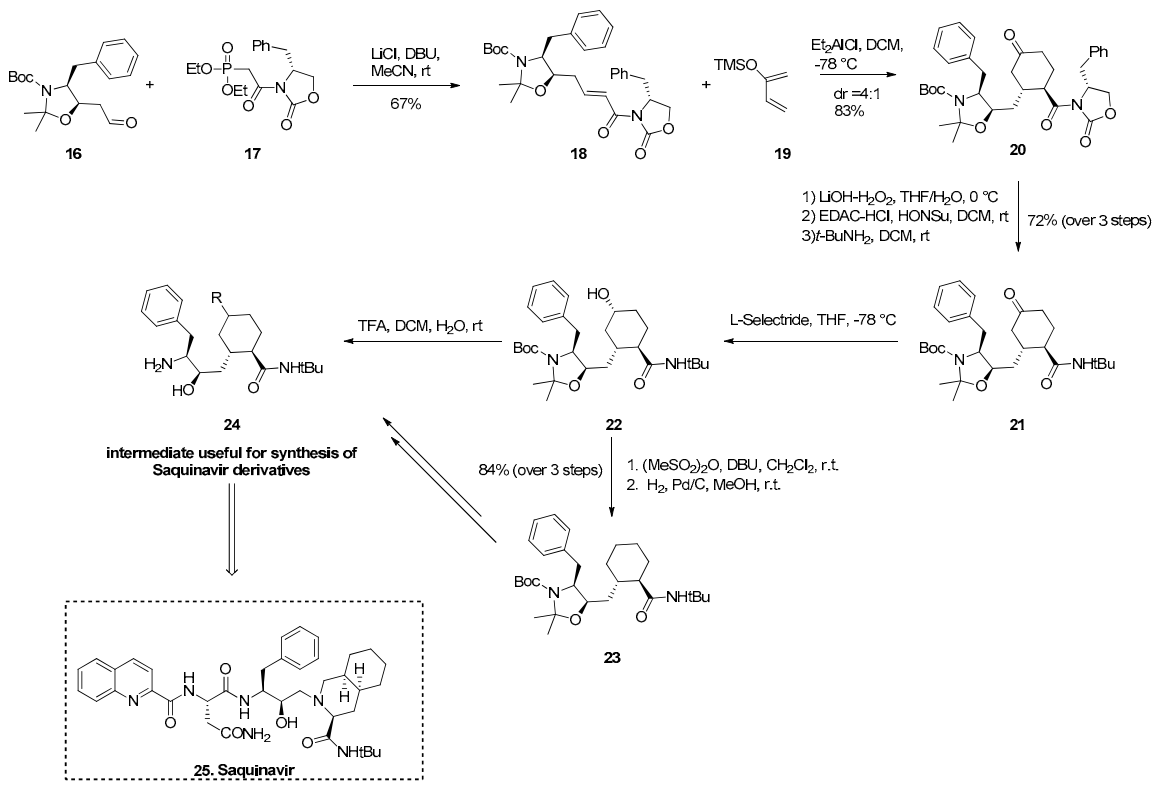

Scheme 7. Synthesis of Saquinavir derivatives via chiral auxiliary-based DAR. 


\subsubsection{Darunavir Derivatives}

In the Arun Ghosh research group, based on the "backbone binding concept" and with the idea to suppress the drug resistance against HIV, a new design strategy was developed. this provided the synthesis of novel HIV PI able to form a strong network of hydrogen bonding interaction with the backbone atoms of HIV-1 protease.

In this framework, in 2006, the FDA-approved DARUNAVIR (DRV) (Prezista ${ }^{\circledR}$ ) [55] was born to fight the HIV. DRV was designed to promote extensive active site interactions with the backbone atoms of the HIV-1 protease active site. It has emerged as the first-line therapy for rescue treatment in the current US Department of Health and Human Service (DHHS) guidelines.

Even if DRV is highly active against multidrug-resistant HIV-1 variants with a dual mechanism of action, as it potently inhibits biologically active dimeric HIV-1 protease and prevents dimerization of protease monomers [59,60], DRV-resistant and HIV-1 variants may result in treatment failure $[61,62]$. Recently, Ghosh et al. reported the design and synthesis of a new class of PIs incorporating a 6-5-5 ring-fused crown-like tetrahydropyranotetrahydrofuran (crown-THF) as the P2 ligand with a hydroxyethyl sulfonamide transitionstate mimic (28b, Scheme 8) [63,64].
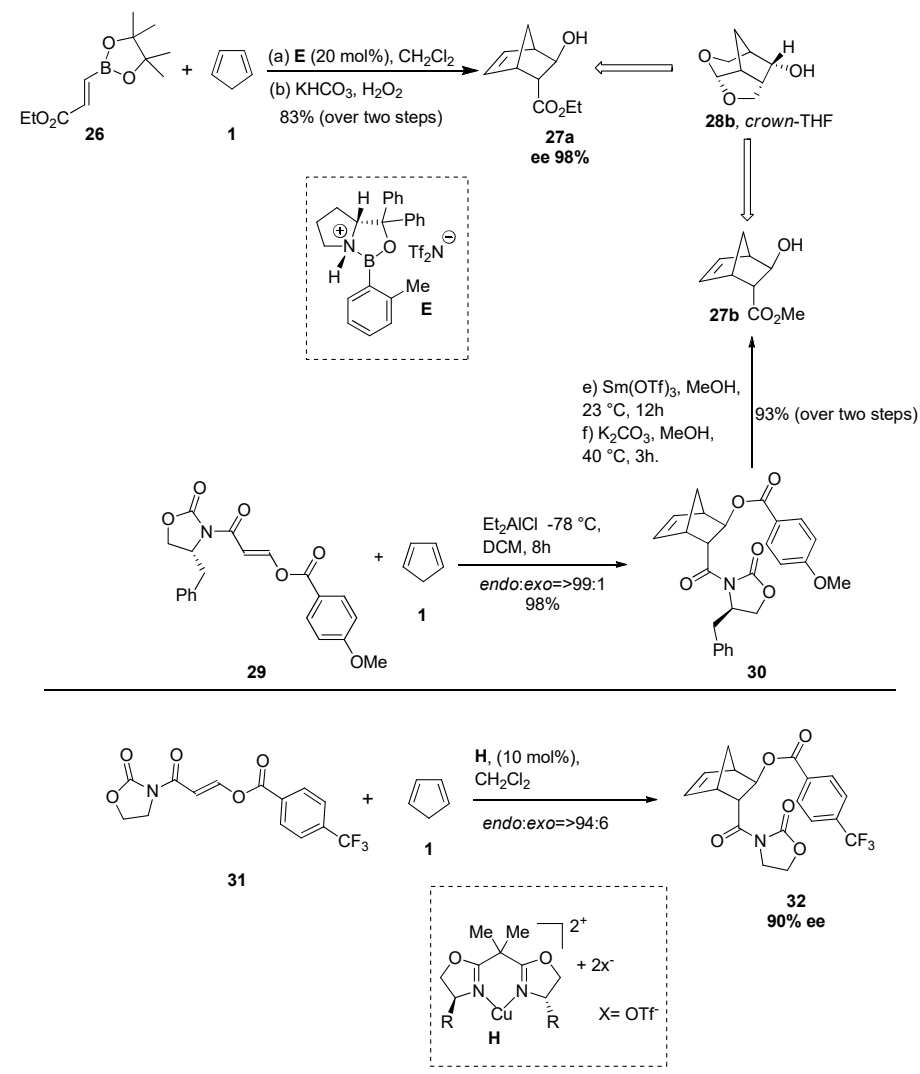

Scheme 8. Synthesis of DAR adducts 27a,b useful for the synthesis of Darunavir derivative 35 .

Herein we focused the attention on two synthetic pathways reported for the synthesis of $28 \mathrm{~b}$; both of them are described in the Scheme 8 and provided the catalytic DAR approach, using in the first strategy the Corey Chiral catalyst (E, Scheme 2) and Evans's chiral auxiliary [19] in the second one. Both strategies allow to obtain the alchools $\mathbf{2 7} \mathbf{a}, \mathbf{b}$ with high enantioselectively ( $>98 \%$ ee).

The first synthesis provided the DAR between the ethyl vinyl boronate $\mathbf{2 6}$ and cyclopentadiene $\mathbf{1}$ in the presence of Corey's chiral catalyst (E Scheme 2) [27,28], affording the key intermediates $27 \mathrm{a}$ in high enantiomeric purity in $80 \%$ yield over two steps on the gram scale. The second strategy provided instead the DARs of chiral 3-(acyloxy)acryloyl oxazolidinones as dienophiles in various LA promoted reactions with cyclopentadiene 1. 
Herein we report the best conditions found so far that provided the DAR between the chiral diene 29 and cyclopentadiene 1 in presence of $\mathrm{Et}_{2} \mathrm{AlCl}$ as LA affording DAR adduct 30 in $98 \%$ of yield. Similar intermediate 32 was reported by Sibi [65]. It was achieved by means of DAR between achiral 3-(acyloxy)acrylates 31 (Scheme 8) and cyclopentadiene 1, using chiral $[\mathrm{Cu}$ (box)]-(OTf) 2 (L, Scheme 4$)$ with good ee $(90 \%)$. The subsequent exposure of the cyclo-adduct 30 to $\mathrm{Sm}(\mathrm{OTf})_{3}$ in $\mathrm{MeOH}$ followed by $\mathrm{K}_{2} \mathrm{CO}_{3}$ in $\mathrm{MeOH}$, provided the corresponding $\beta$-hydroxy ester $\mathbf{2 7 b}$. Alcohols $\mathbf{2 7} \mathbf{a}, \mathbf{b}$ were then treated with TBSOTf to afford TBS ether counterpart, and then they were, in turn, converted to bicyclic acetal 33 in a three-step sequence involving (1) the reduction of the ester with LAH, (2) one-pot oxidative cleavage of the olefin and (3) the reduction of the resulting aldehyde with DIBAL-H. The resulting mixture of lactol (2:1) was treated with TFA to furnish a bridged tricyclic derivative whose TBS group was removed in tetrabutylammonium fluoride (TBAF), giving the exo-alcohol 28a with good overall yield. This exo-alcohol was then converted to endo-alcohol $\mathbf{2 8 b}$ by Dess-Martin oxidation, followed by a reduction of the resulting ketone with $\mathrm{NaBH}_{4}$, thus affording the desired bridged tricyclic ligand, $(3 S, 3 \mathrm{a} S, 5 \mathrm{R}, 7 \mathrm{a} S, 8 S)$-hexahydro-4H-3,5methanofuro[2,3-b]-pyran-8-ol 28b, which, via carbonate activation with 4-nitrophenyl chloroformate, and subsequent reaction with the suitable (R)-hydroxysulfonamide isostere, afforded the inhibitor 35 (Scheme 9).
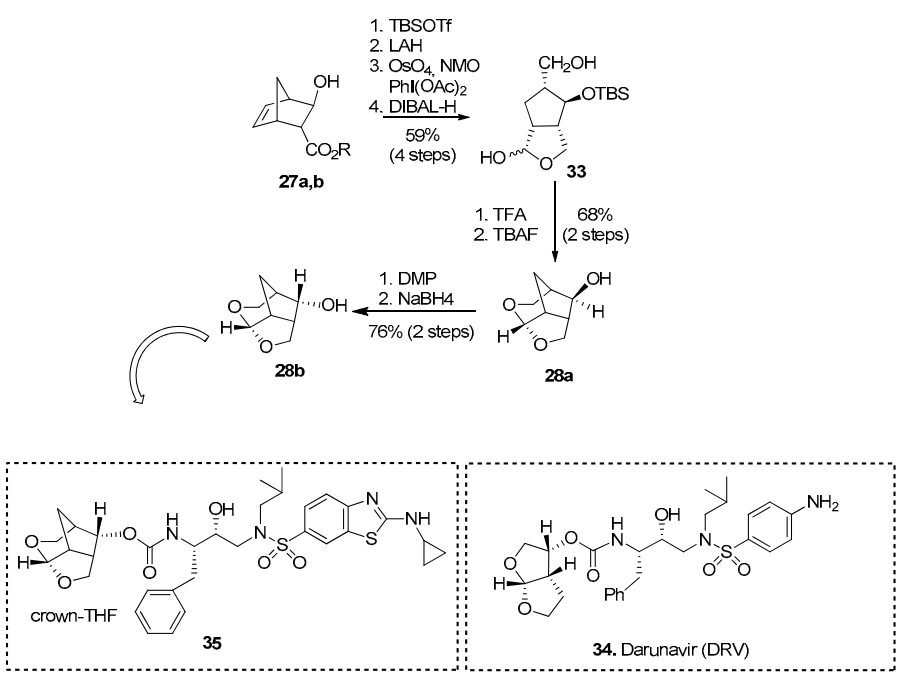

Scheme 9. Synthesis of Darunavir derivative 35.

\subsubsection{Synthesis of Oseltamivir}

Influenza viruses are respiratory pathogens responsible for seasonal influenza and influenza pandemic. The therapeutic efficacy of current vaccines and drugs is particularly limited, due to the multidrug-resistant influenza viruses' phenomenon. Actually, there are two classes of FDA-approved molecules against influenza virus, namely M2 channel blockers and neuraminidase inhibitors. Oseltamivir phosphate (Tamiflu), a neuraminidase inhibitor for the treatment of both type A and type B human influenza, is one of the most promising drugs [66]. Yujiro Hayashi et al. proposed a multicomponent (MC) approach for the synthesis of Oseltamivir based on the condensation of alkoxy-aldehyde, nitroalkene and diethyl vinyl-phosphonate derivative in the presence of diphenylprolinol silyl ether as the catalyst. This and other reactions concerning the MC synthesis of antiviral agents have been recently reported [67]. Due to the increase of in drug-resistance phenomena, as well as novel Influenza virus mutations, novel mechanisms for the inhibition of human influenza virus have been explored [10-13].

Oseltamivir phosphate (Gilead's Tamiflu, marketed by Roche) $[66,68]$ inhibits NA by strongly binding its active site, showing activity in the nanomolar range. Even if the molecule appears to be very small, the discovery of a practical synthetic route able to provide the quantity required worldwide is challenging [69]. Several synthetic approaches 
were exploited [70], as reviewed from Gong and Xu in 2008 and from Cloudius R. Sagandira and coworkers in 2020 [71]. Herein we focus the attention on DAR-based approaches, since, considering Oseltamivir as a cyclohexene derivative, asymmetric DAR should be an ideal option. Since the first synthesis proposed from Roche [72] provided enzymatic resolution, several research groups have tried to develop asymmetric synthesis by applying the asymmetric DAR approach. In Scheme 10 is reported the retrosynthetic approach for Oseltamivir, starting from high enantiopure DAR adduct 37-39a,b and $\mathbf{6 , 6} \mathbf{6}^{\prime}$. The complete synthesis is described in detail in the Schemes 11-14.

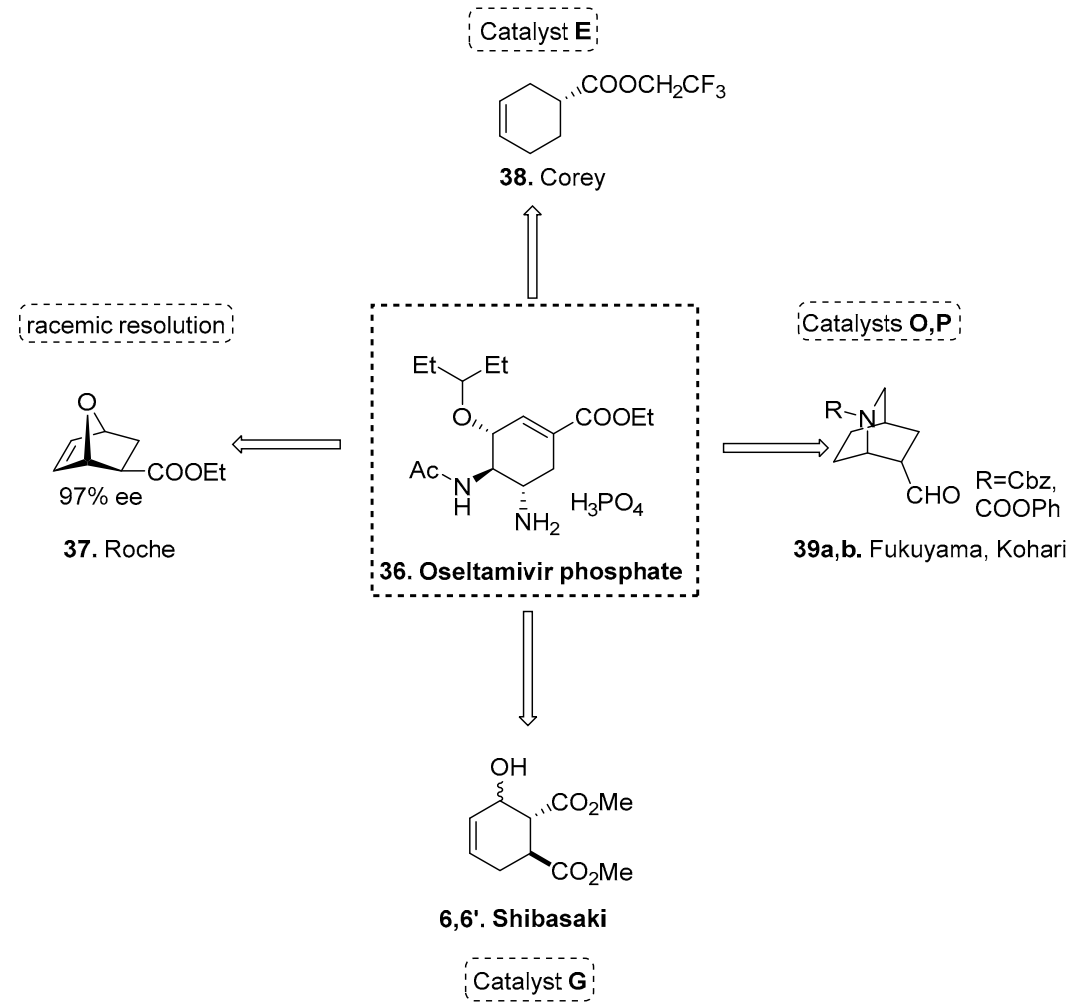

Scheme 10. Retrosynthetic approach of Oseltamivir phosphate via enantiopure DAR adducts 37-39 and $6,6^{\prime}$.

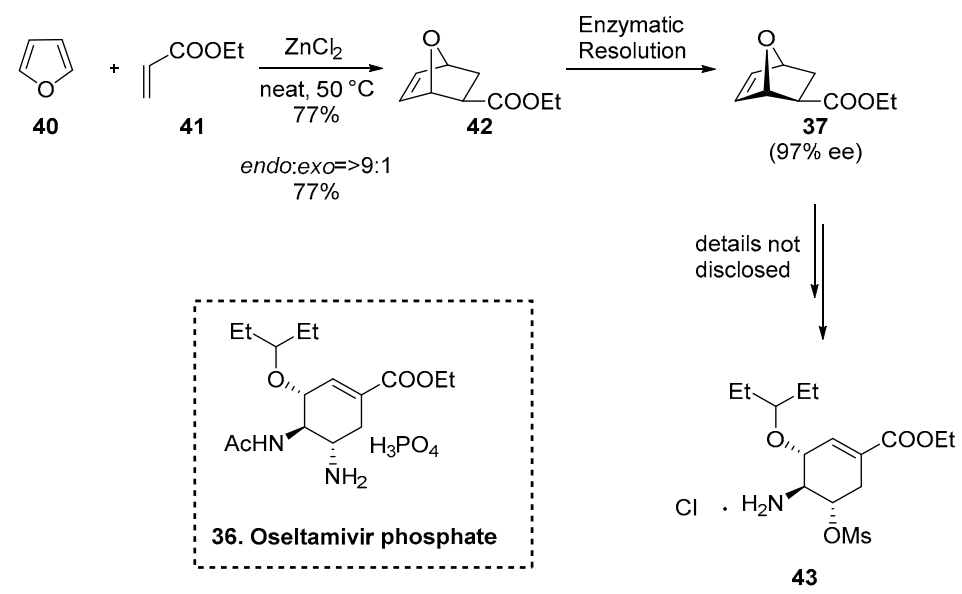

Scheme 11. Synthesis of Oseltamivir phosphate by Roche based on racemic DAR adduct 44. 


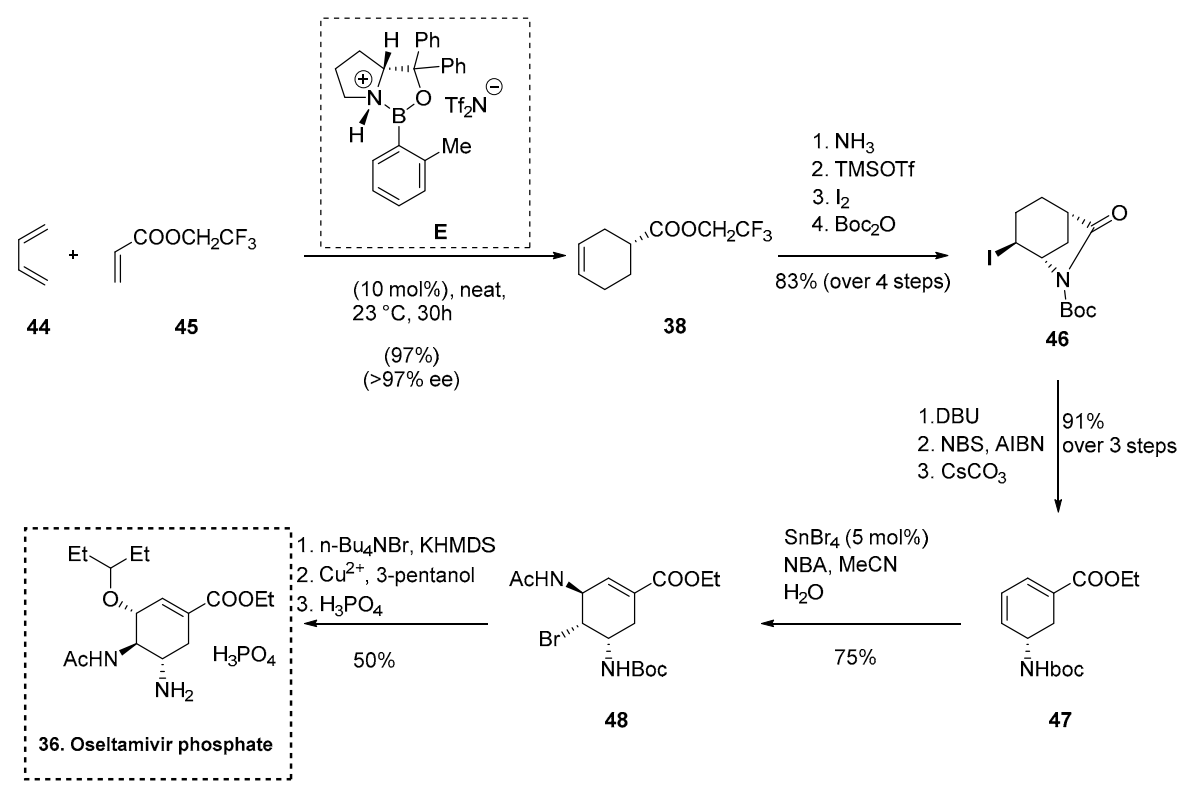

Scheme 12. Synthesis of Oseltamivir phosphate by Corey based on enantiopure DAR adduct 48.

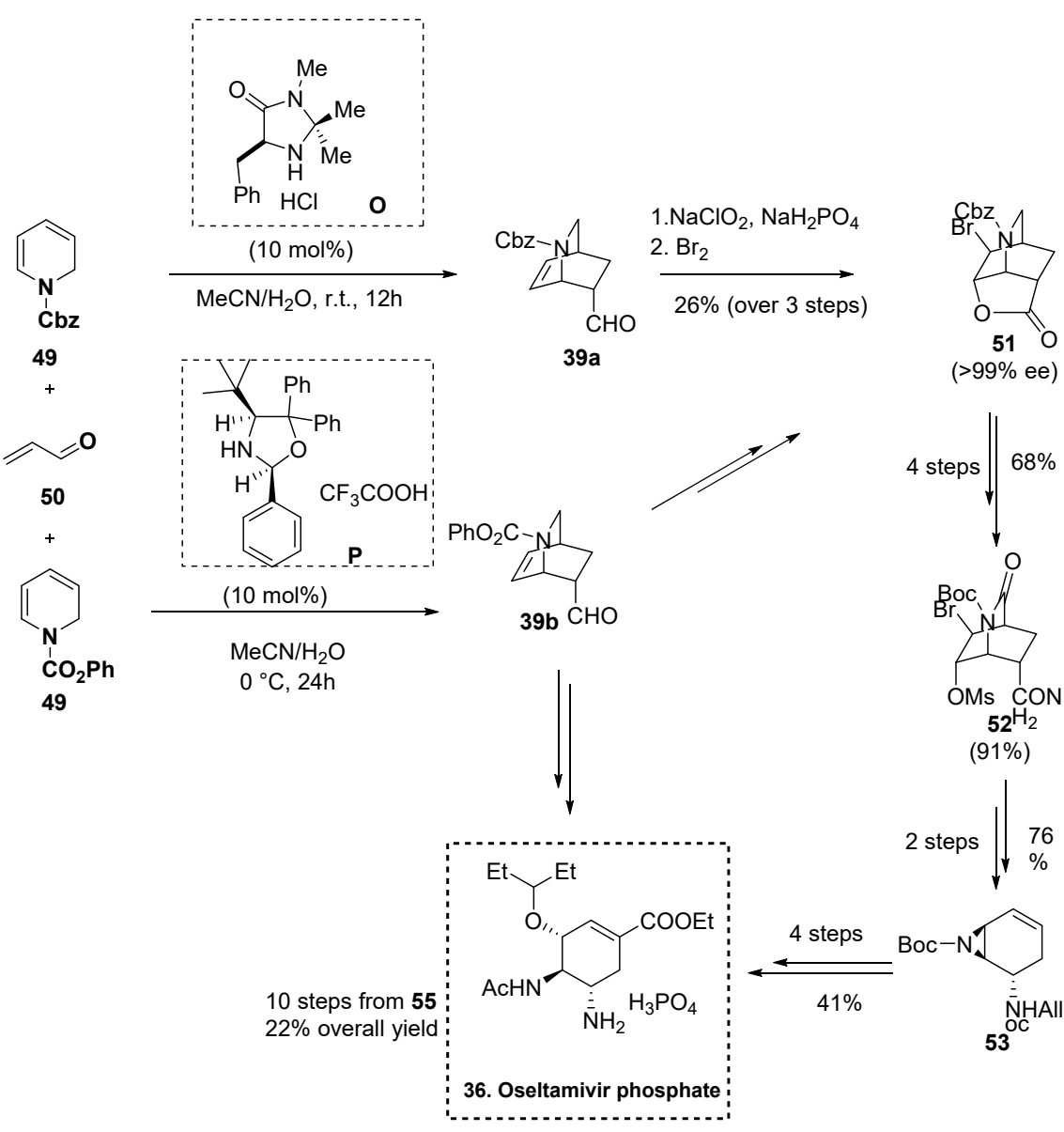

Scheme 13. Synthesis of Oseltamivir phosphate based on enantiopure isoquinuclidine $54 a, b$. 


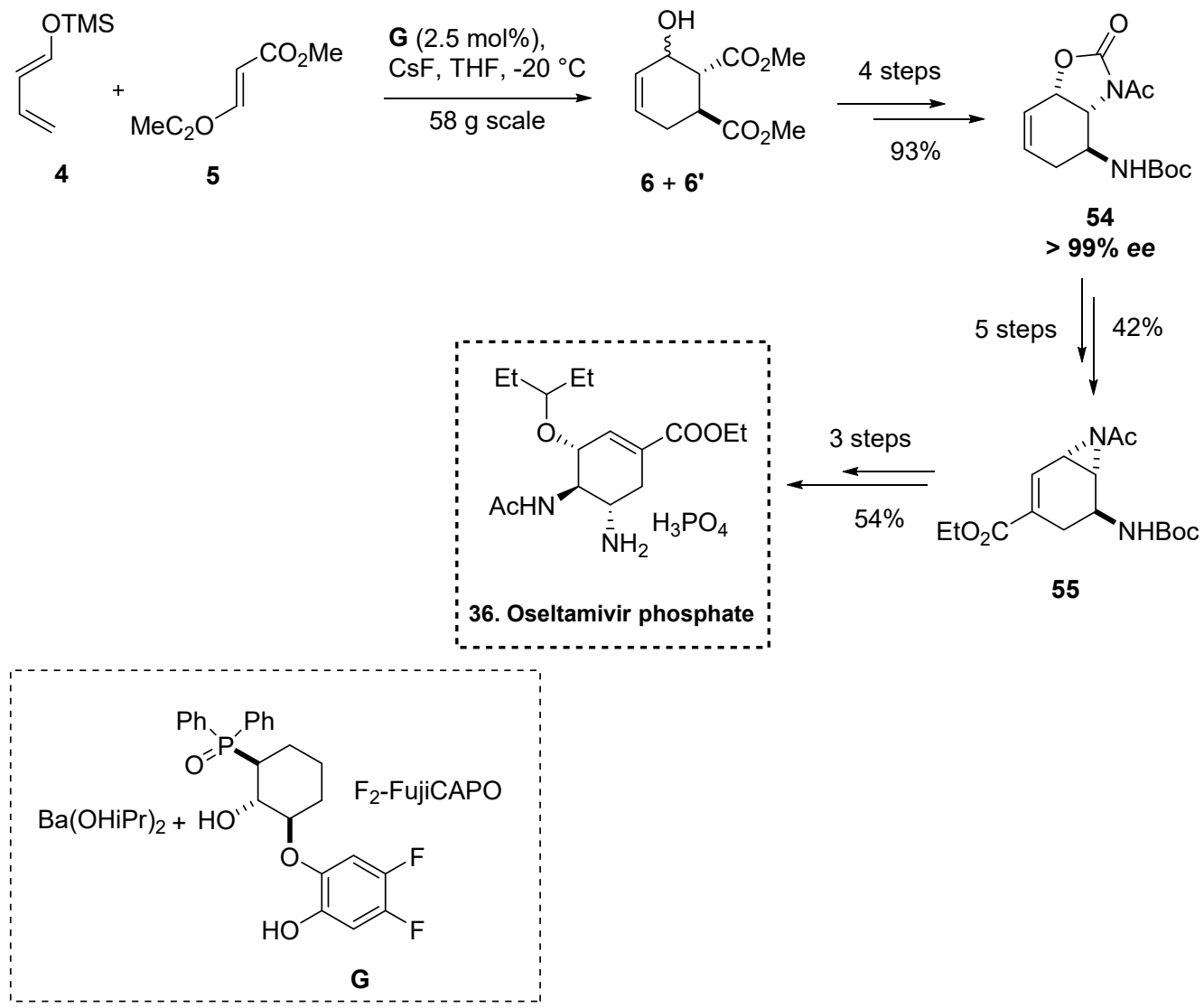

Scheme 14. Synthesis of Oseltamivir phosphate from Shibasaki.

The synthesis by Roche (Scheme 11) started from racemic DAR between furan 40 and ethyl acrylate 41 catalyzed from $\mathrm{ZnCl}_{2}$ affording the exo-42 $(\mathrm{dr}=9: 1)$. Subsequent enzymatic resolution allowed researchers to obtain the desired $\mathrm{R}$ isomer 37 with $97 \%$ ee at $75 \%$ conversion ( $20 \%$ yield). Then the well-known transformation $[72,73]$ allowed them to obtain the Oseltamivir phosphate 36.

In 2006, Corey reported an elegant synthesis of Oseltamivir phosphate 36 [74] based on key catalytic asymmetric DAR between butadiene $\mathbf{4 4}$ and trifluoroethylacrilate 45 in the presence of $10 \%$ triflimide-activated oxazaborolidine catalyst $\mathbf{E}$, affording the DAR counterpart 38 with excellent yield and ee ( $97 \%$ yield, $>97 \%$ ee). The high enantioselectivity was explained by a transition state model, in which butadiene approached the activated dienophile from the Re-face opposite the shielding phenyl group of the catalyst. Remarkably, the initial DAR step is easily carried out at room temperature on a multigram scale with recovery of correspondent precatalyst. The next reactions in the sequence involved (a) ammonolysis of $\mathbf{3 8}$ and (b) Iodolactamization, using the Knapp protocol [74], and N-Boc insertion afforded derivative 46. Then (a) dehydroiodination with 1,8-diazabicyclo-[5.4.0]undec-7-ene (DBU), (b) allylical bromination and (c) treatment with cesium carbonate in ethanol afforded the diene ethyl ester 47 . The next step in the synthetic sequence was a $\mathrm{SnBr}_{4}$-catalyzed bromoacetamidation completely regio and stereoselective, using N-bromoacetamide (NBA), that converted the diene 47 to the bromodiamide 48 , and, in turn cyclized it to the $\mathrm{N}$-acetylaziridine counterpart, which, after treatment with 3-pentanol solution containing a catalytic amount of cupric triflate, removal of the Boc group and salt formation with phosphoric acid in ethanol afforded 36 (Scheme 12).

Both Fukuyama in 2006 and Kohari in 2010 speculated that chiral isoquinuclidine (39a,b, Scheme 13) was an efficient synthetic intermediate for Oseltamivir phosphate 36 . The first applied the enantioselective DAR between dihydropiridine 49 and acrolein 50 in presence of MacMillan Catalyst (O, Scheme 5). As mentioned in Section 2.4, even if he obtained high enantioselectity (>99\% ee), the reaction proceeded in low yield ( $26 \%)$. Later, Kohari 
improved the yield of this reaction by using 2-phenyl-4-tert-butyl-5,5-diphenyloxazolidine with $\mathrm{CF}_{3} \mathrm{CO}_{2} \mathrm{H}$ (P, Scheme 7) that exhibited a high degree of enantioselectivity (up to $>99 \%$ ee) and good chemical yield (up to $90 \%$ ) in the DAR reaction of 1,2-dihydropyridines 49 with acrolein 50. As Fukuyama reported [75], the resulting DAR adduct 39a was subjected to Kraus oxidation, bromo lactonization [76] and recrystallization, affording pure $\mathbf{5 1}$ ( $>99 \%$ ee) in $26 \%$ yield. The subsequent 10 reported steps [75] afforded Oseltamivir phosphate 36 in $22 \%$ overall yield.

Shibasaki [30] proposed the synthesis of Oseltamivir phosphate based on chiral DAR adduct between diene 4 and methyl fumarate 5 , performed in a big scale (58 g), catalyzed from $\mathrm{F} 2$-FujiCAPO and $\mathrm{Ba}(\mathrm{OiPr})_{2}(\mathbf{G}$, Scheme 3$)$, affording DA adducts $\mathbf{6}, \mathbf{6}^{\prime}$ with high enantioselectivity ( $96 \%$ ee) in the presence of $\mathrm{CsF}$ as additive. The (exo- $6^{\prime}$ isomer) decomposed during the next transformations, which allowed us to obtain the cyclic carbamate 54 in $93 \%$ of yield after four steps ( $96 \%$ ee); further recrystallized from $\mathrm{CH}_{2} \mathrm{Cl}_{2} /$ cyclopenthyl methyl ether increased the ee up to $99 \%$. Moreover, 54 was converted into $\mathrm{N}$-acyl aziridine 55 in five steps $(42 \%)$, and the subsequent aziridine opening performed best by using $\mathrm{BF}_{3} \cdot \mathrm{OEt}_{2}$ to afford Boc-protected (-)-Oseltamivir. Cleavage of the Boc group with TFA and salt formation with phosphoric acid produced Tamiflu (36 in 73\% yield) (Scheme 14).

\subsection{DA Applied for the Synthesis of Natural Compound Endowing Antiviral Activity}

Using the Nicolaou words, the DAR has afforded numerous and unparalleled solutions to a diverse range of synthetic puzzles provided by nature in the form of natural products [49]. Even if there are several examples of the application of this reaction applied to natural compounds endowing antiviral activity-referred, for example, to anti-influenza (-)-Cytisine derivatives [77] and Sorbicatechol [78] to the Anti-HIV agent Siamenol [79] herein we report one selected example in which the asymmetric DAR protocol was applied, using chiral diene in the presence of LA to the synthesis of anti-influenza wickerol.

\section{Synthesis of Wickerols}

Wickerol A and wickerol B are bioactive diterpenoids that were isolated from the fungus Trichoderma atroviride FK-3849 by Ōmura and Shiomi [80]. Wickerol A (60, Scheme 15), differently to wickerol B (61, Scheme 15) resulted in being highly active against the type A/H1N1 influenza virus. Both natural products are endowed with a unique tetracyclic carbon skeleton that comprises two adjacent quaternary carbons and seven or eight stereocenters. In regard to the challenge posed by the wickerols, to the best of our knowledge, only three synthetic pathways have been disclosed to date [81-83]. Herein we are interested in a recent approach published from Shu-An Liu [82]. This author published an asymmetric synthesis of wickerols with a retrosynthetic approach that is described in Scheme 15. This synthesis, as defined by the authors, could be considered a testament to the power of catalysis in cycloadditions. Specifically, key intermediate 58 (Scheme 15), which contains all carbons of the wickerols, save two, could be accessed with a DAR between the chiral diene $\mathbf{6 1}$ and the known enone $\mathbf{6 0}$ in the presence of $\mathrm{AlBr}_{3} / \mathrm{AlMe}_{3}$ [84,85]. The chiral diene, in turn, would be derived from known ketone $\mathbf{6 2}$, which is readily accessible from geraniol via Sharpless-epoxidation, Yamamoto rearrangement [86] and carbonyl-ene cyclization [87]. 


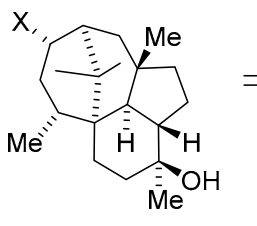

$\mathrm{X}=\mathrm{H}$ wickerol $\mathrm{A}(56)$ $\mathrm{X}=\mathrm{OH}$ wickerol $\mathrm{B}(57)$

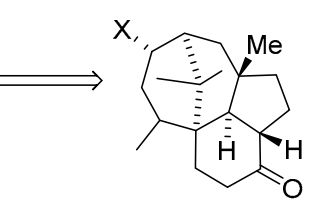

58

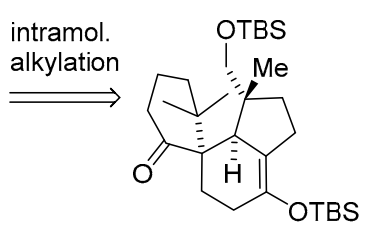

59

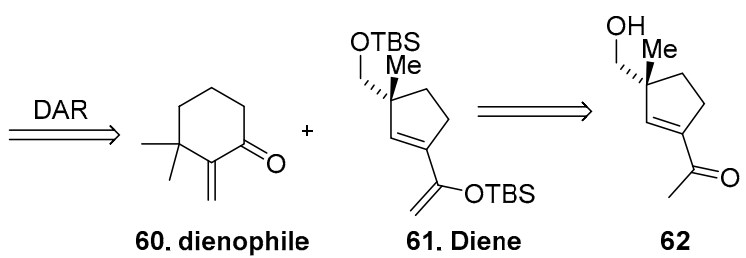

Scheme 15. Retrosynthetic approach to the synthesis of wickerol A 56 via DAR in the presence of chiral diene 61.

\section{Conclusions}

The outbreak of COVID-19 has once more emphasized the impact of viral infections on human health. This review highlighted how the asymmetric DAR could be a key step for the synthesis of important antiviral agents, using chiral LA, chiral dienophiles or organocatalysts. Any specific drug against coronavirus should target the virus and its respiratory and cardiovascular effects. While discovery of this magic bullet is underway, the current pandemic should enhance our preparedness for the next time, when urgency will knock at the door again. The scale-up of small molecules, even under the pandemic's pressure, could be a challenge, and this challenge could be approached only with a good knowledge of organic chemistry. This manuscript has furnished a further perspective of DAR, hoping that this perspective will stimulate further use of this old but very actual reaction in the discovery of novel chemical entities endowing antiviral activity. Accordingly, we strongly believe that a crisis such as the one caused by COVID-19 will also open up important opportunities for those considering this reaction and its asymmetric version as a possible solution for current organic chemistry issues in the antiviral field.

Author Contributions: Conceptualization, A.G. and B.M.B.; writing—original draft preparation, A.G. and B.M.B.; writing-review and editing, A.G. and B.M.B.; funding acquisition, B.M.B. All authors have read and agreed to the published version of the manuscript.

Funding: The project "Estratti da legni antichi di foreste VEtuste per un uso innovativo nel Restauro dei beni culturali" A0375-2020-36776 Progetti Gruppi di Ricerca 2020, Regione Lazio is acknowledged.

Conflicts of Interest: The authors declare no conflict of interest.

\section{References}

1. De Nino, A.; Maiuolo, L.; Merino, P.; Nardi, M.; Procopio, A.; Roca-López, D.; Russo, B.; Algieri, V. Efficient Organocatalyst Supported on a Simple Ionic Liquid as a Recoverable System for the Asymmetric Diels-Alder Reaction in the Presence of Water. ChemCatChem 2015, 7, 830-835. [CrossRef]

2. Carruthers, W. Cycloaddition Reactions in Organic Synthesis; Pergamon: Oxford, UK, 1990; 359p.

3. Constantino, A.F.; Francisco, C.S.; Cubides-Roman, D.C.; Lacerda, V. Hetero-Diels-Alder Reactions in the Synthesis of Biologically Active Nitrogen Compounds: A Review. Curr. Org. Synth. 2017, 15, 84-104. [CrossRef]

4. Gregoritza, M.; Brandl, F.P. The Diels-Alder reaction: A powerful tool for the design of drug delivery systems and biomaterials. Eur. J. Pharm. Biopharm. 2015, 97, 438-453. [CrossRef]

5. Arumugam, S.; Popik, V.V. Light-induced hetero-diels-alder cycloaddition: A facile and selective photoclick reaction. J. Am. Chem. Soc. 2011, 133, 5573-5579. [CrossRef]

6. Pałasz, A. Recent Advances in Inverse-Electron-Demand Hetero-Diels-Alder Reactions of 1-Oxa-1,3-Butadienes. Top. Curr. Chem. 2016, 374, 24-61. [CrossRef]

7. Quadrelli, P.; Moiola, M. Cycloaddition Reactions for Antiviral Compounds, 1st ed.; Elsevier: Amsterdam, The Netherlands, 2019; 83p. 
8. Slagman, S.; Fessner, W.D. Biocatalytic routes to anti-viral agents and their synthetic intermediates. Chem. Soc. Rev. 2021, 50, 1968-2009. [CrossRef]

9. Bizzarri, B.M.; Fanelli, A.; Botta, L.; De Angelis, M.; Palamara, A.T.; Nencioni, L.; Saladino, R. Aminomalononitrile inspired prebiotic chemistry as a novel multicomponent tool for the synthesis of imidazole and purine derivatives with anti-influenza A virus activity. RSC Adv. 2021, 11, 30020-30029. [CrossRef]

10. Zippilli, C.; Botta, L.; Bizzarri, B.M.; Nencioni, L.; De Angelis, M.; Protto, V.; Giorgi, G.; Baratto, M.C.; Pogni, R.; Saladino, R. Laccase-Catalyzed 1,4-Dioxane-Mediated Synthesis of Belladine N-Oxides with Anti-Influenza A Virus Activity. Int. J. Mol. Sci. 2021, 22, 1337. [CrossRef]

11. Bizzarri, B.M.; Fanelli, A.; Piccinino, D.; De Angelis, M.; Dolfa, C.; Palamara, A.T.; Nencioni, L.; Zippilli, C.; Crucianelli, M.; Saladino, R. Synthesis of Stilbene and Chalcone Inhibitors of Influenza A Virus by SBA-15 Supported Hoveyda-Grubbs Metathesis. Catalysts 2019, 9, 983. [CrossRef]

12. Bizzarri, B.M.; Botta, L.; Capecchi, E.; Celestino, I.; Checconi, P.; Palamara, A.T.; Nencioni, L.; Saladino, R. Regioselective IBXMediated Synthesis of Coumarin Derivatives with Antioxidant and Anti-influenza Activities. J. Nat. Prod. 2017, 80, 3247-3254. [CrossRef]

13. Botta, G.; Bizzarri, B.M.; Garozzo, A.; Timpanaro, R.; Bisignano, B.; Amatore, D.; Palamara, A.T.; Nencioni, L.; Saladino, R. Carbon nanotubes supported tyrosinase in the synthesis of lipophilic hydroxytyrosol and dihydrocaffeoyl catechols with antiviral activity against DNA and RNA viruses. Bioorg. Med. Chem. 2015, 23, 5345-5351. [CrossRef] [PubMed]

14. Sirous, H.; Fassihi, A.; Brogi, S.; Campiani, G.; Christ, F.; Debyser, Z.; Gemma, S.; Butini, S.; Chemi, G.; Grillo, A.; et al. Synthesis, Molecular Modelling and Biological Studies of 3-hydroxy-pyrane-4-one and 3-hydroxy-pyridine-4-one Derivatives as HIV-1 Integrase Inhibitors. Med. Chem. 2019, 15, 755-770. [CrossRef] [PubMed]

15. Ghosh, A.K.; Grillo, A.; Raghavaiah, J.; Kovela, S.; Johnson, M.E.; Kneller, D.W.; Wang, Y.F.; Hattori, S.-I.; Higashi-Kuwata, N.; Weber, I.T.; et al. Design, Synthesis, and X-ray Studies of Potent HIV-1 Protease Inhibitors with P2-Carboxamide Functionalities. ACS Med. Chem. Lett. 2020, 11, 1965-1972. [CrossRef] [PubMed]

16. De Francesco, R.; Donnici, E.; Guidotti, L.; Iannacone, M.; Di Fabio, R.; Summa, V.; Prandi, A.; Randazzo, P.; Ivanova Bencheva, L.; De Mtteo, M.; et al. Oxalamido-Substituted Triciclic Inhibitors of Hepatitis B Virus. WO Patent WO2020234483A1, 26 November 2020.

17. De Francesco, R.; Donnici, L.; Guidotti, L.; Iannaccone, M.; Di Fabio, R.; Summa, V.; Prandi, A.; Randazzo, P.; Gornati, D.; Grillo, A.; et al. Tricyclic Inhibitors of Hepatitis B Virus. WO Patent WO2020030781A1, 13 February 2020.

18. Ghosh, A.K.; Grillo, A.; Kovela, S.; Brindisi, M. Asymmetric Diels-Alder reaction of 3-(acyloxy)acryloyl oxazolidinones: Optically active synthesis of a high-affinity ligand for potent HIV-1 protease inhibitors. RSC Adv. 2019, 9, 41755-41763. [CrossRef]

19. Evans, D.A.; Chapman, K.T.; Bisaha, J. New asymmetric Diels-Alder cycloaddition reactions. Chiral alpha, beta-Unsaturated Carboximides as practical chiral acrylate and crotonate dienophile synthons. J. Am. Chem. Soc. 1984, 106, 4261-4263. [CrossRef]

20. Du, H.; Ding, K. Asymmetric Catalysis of Diels-Alder Reaction. ChemInform 2010, 41, 1-58. [CrossRef]

21. Hashimoto, S.; Komeshima, N.; Koga, K. Asymmetric Diels-Alder reaction catalysed by chiral alkoxyaluminium dichloride. J. Chem. Soc. Chem. Commun. 1979, 10, 437-438. [CrossRef]

22. Bao, J.; Wulff, W.D.; Rheingold, A.L. Vaulted Biaryls as Chiral Ligands for Asymmetric Catalytic Diels-Alder Reactions. J. Am. Chem. Soc. 1993, 115, 3814-3815. [CrossRef]

23. Bao, J.; Wulff, W.D.; Dominy, J.B.; Fumo, M.J.; Grant, E.B.; Rob, A.C.; Whitcomb, M.C.; Yeung, S.M.; Ostrander, R.L.; Rheingold, A.L. Synthesis, resolution, and determination of absolute configuration of a vaulted 2,2'-binaphthol and a vaulted 3,3'-biphenanthrol (VAPOL). J. Am. Chem. Soc. 1996, 118, 3392-3405. [CrossRef]

24. Kobayashi, S.; Murakami, M.; Harada, T.; Mukaiyama, T. The Asymmetric Diels-Alder Reaction of $\alpha, \beta$-Unsaturated Aldehydes with Dienes using a chiral boron reagent as a catalyst. Chem. Lett. 1991, 20, 1341-1344. [CrossRef]

25. Hayashi, Y.; Rohde, J.J.; Corey, E.J.; March, R.V. A Novel Chiral Super-Lewis Acidic Catalyst for Enantioselective Synthesis. J. Am. Chem. Soc. 1996, 118, 5502-5503. [CrossRef]

26. Corey, E.J.; Shibata, T.; Lee, T.W. Asymmetric Diels-Alder Reactions Catalyzed by a Triflic Acid Activated Chiral Oxazaborolidine. J. Am. Chem. Soc. 2002, 124, 3808-3809. [CrossRef]

27. Mukherjee, S.; Corey, E.J. [4 + 2] Cycloaddition Reactions Catalyzed by a Chiral Oxazaborolidinium Cation. Reaction Rates and Diastereo-, Regio-, and Enantioselectivity Depend on Whether Both Bonds Are Formed Simultaneously. Org. Lett. 2010, 12, 1024-1027. [CrossRef]

28. Mahender Reddy, K.; Bhimireddy, E.; Thirupathi, B.; Breitler, S.; Yu, S.; Corey, E.J. Cationic Chiral Fluorinated Oxazaborolidines. More Potent, Second-Generation Catalysts for Highly Enantioselective Cycloaddition Reactions. J. Am. Chem. Soc. 2016, 138, 2443-2453. [CrossRef]

29. Maruoka, K.; Murase, N.; Yamamoto, H. Chiral helical Lewis acids for asymmetric Diels-Alder catalysts. J. Org. Chem. 1993, 58, 2938-2939. [CrossRef]

30. Yamatsugu, K.; Yin, L.; Kamijo, S.; Kimura, Y.; Kanai, M.; Shibasaki, M. A Synthesis of Tamiflu by using a Barium-Catalyzed Asymmetric Diels-Alder-Type reaction. Angew. Chem. Int. Ed. Engl. 2009, 48, 1070-1076. [CrossRef]

31. Corey, E.J.; Kurti, L. Enantioselective Chemical Synthesis: Methods, Logic, and Practice; Elsevier: Amsterdam, The Netherlands, 2013; 151p.

32. Carreira, E.M.; Kvaerno, L. Classics in Stereoselective Synthesis; John Wiley \& Sons: Hoboken, NJ, USA, 2009; 158p. 
33. Walsh, P.J.; Kozlowski, M.C. Fundamentals of Asymmetric Catalysis; University Science Books: Sausalito, CA, USA, 2009; 549p.

34. Narasaka, K.; Inoue, M.; Okada, N. Asymmetric Diels-Alder reaction promoted by a chiral titanium reagent. Chem. Lett. 1986, 15, 1109-1112. [CrossRef]

35. Corey, E.J.; Imai, N.; Zhang, H.Y. Designed Catalyst for Enantioselective Diels-Alder addition from a C2-symmetric chiral bis(oxazoline)-Fe(III) complex. J. Am. Chem. Soc. 1991, 113, 728-729. [CrossRef]

36. Corey, E.J.; Ishihara, K. Highly enantioselective catalytic Diels-Alder addition promoted by a chiral bis(oxazoline)-magnesium complex. Tetrahedron Lett. 1992, 33, 6807-6810. [CrossRef]

37. Corey, E.J.; Imwinkelried, R.; Pikul, S.; Xiang, Y.B. Practical enantioselective Diels-Alder and aldol reactions using a new chiral controller system. J. Am. Chem. Soc. 1989, 111, 5493-5495. [CrossRef]

38. Evans, D.A.; Barnes, D.M.; Johnson, J.S.; Lectka, T.; Matt, P.V.; Miller, S.J.; Murry, J.A.; Norcross, R.D.; Shaughnessy, E.A.; Campos, K.R. Bis(oxazoline) and Bis(oxazolinyl)pyridine Copper Complexes as Enantioselective Diels-Alder Catalysts: Reaction Scope and Synthetic Applications. J. Am. Chem. Soc. 1999, 121, 7582-7594. [CrossRef]

39. Evans, D.A.; Murry, J.A.; Von Matt, P.; Norcross, R.D.; Miller, S.J. C 2 -Symmetric Cationic Copper(II) Complexes as Chiral Lewis Acids: Counterion Effects in the Enantioselective Diels-Alder Reaction. Angew. Chem. Int. Ed. Engl. 1995, 34, 798-800. [CrossRef]

40. Kobayashi, S.; Ishitani, H. Lanthanide(III)-Catalyzed Enantioselective Diels-Alder Reactions. Stereoselective Synthesis of Both Enantiomers by Using a Single Chiral Source and a Choice of Achiral Ligands. J. Am. Chem. Soc. 1994, 116, 4083-4084. [CrossRef]

41. Ghosh, A.K.; Matsuda, H. Counterions of BINAP-Pt(II) and -Pd(II)Complexes: Novel Catalysts for Highly Enantioselective Diels-Alder Reaction. Org. Lett. 1999, 1, 2157-2159. [CrossRef]

42. Ahrendt, K.A.; Borths, C.J.; MacMillan, D.W.C. New strategies for organic catalysis: The first highly enantioselective organocatalytic Diels-Alder reaction. J. Am. Chem. Soc. 2000, 122, 4243-4244. [CrossRef]

43. Riant, O.; Kagan, H.B. Asymmetric Diels-Alder reaction catalyzed by chiral bases. Tetrahedron Lett. 1989, 30, 7403-7406. [CrossRef]

44. Suttibut, C.; Kohari, Y.; Igarashi, K.; Nakano, H.; Hirama, M.; Seki, C.; Matsuyama, H.; Uwai, K.; Takano, N.; Okuyama, Y.; et al. A highly enantioselective Diels-Alder reaction of 1,2-dihydropyridine using a simple b-amino alcohol organocatalyst for a practical synthetic methodology of oseltamivir intermediate. Tetrahedron Lett. 2011, 52, 4745-4748. [CrossRef]

45. Nakano, H.; Tsugawa, N.; Fujita, R. The highly enantioselective Diels-Alder reaction of 1,2-dihydropyridine using chiral cationic palladium-phosphinooxazolidine catalyst for the synthesis of chiral isoquinuclidines. Tetrahedron Lett. 2005, 46, 5677-5681. [CrossRef]

46. Nakano, H.; Tsugawa, N.; Takahashi, K.; Okuyama, Y.; Fujita, R. An efficient synthetic methodology of chiral isoquinuclidines by the enantioselective Diels-Alder reaction of 1,2-dihydropyridines using chiral cationic palladium-phosphinooxazolidine catalyst. Tetrahedron 2006, 62, 10879-10887. [CrossRef]

47. Corey, E. Catalytic Enantioselective Diels-Alder Reactions: Methods, Mechanistic Fundamentals, Pathways, and Applications. Angew. Chem. Int. Ed. Engl. 2002, 41, 1650-1667. [CrossRef]

48. Brocksom, T.J.; Nakamura, J.; Maria, L.; Brocksom, U. The Diels-Alder Reaction: An Update. J. Braz. Chem. Soc. 2001, 12, 597-622. [CrossRef]

49. Nicolaou, K.C.; Snyder, S.A.; Montagnon, T.; Vassilikogiannakis, G. The Diels-Alder reaction in total synthesis. Angew. Chem. Int. Ed. 2002, 41, 1668-1698. [CrossRef]

50. Funel, J.-A.; Abele, S. Industrial Applications of the Diels-Alder Reaction. Angew. Chem. Int. Ed. Engl. 2013, 52, 2-44. [CrossRef]

51. Daluge, S.; Vince, R. Synthesis of Carbocyclic Aminonucleosides. J. Org. Chem. 1978, 43, 2311-2320. [CrossRef]

52. Griffiths, G.J.; Previdoli, F.E. Diels-Alder reaction of methanesulfonyl cyanide with cyclopentadiene. Industrial synthesis of 2-azabicyclo[2.2.1]hept-5-en-3-one. J. Org. Chem. 1993, 58, 6129-6131. [CrossRef]

53. Ruebsam, F.; Murphy, D.E.; Tran, C.V.; Li, L.S.; Zhao, J.; Dragovich, P.S.; McGuire, H.M.; Xiang, A.X.; Sun, Z.; Ayida, B.K.; et al. Discovery of tricyclic 5,6-dihydro-1H-pyridin-2-ones as novel, potent, and orally bioavailable inhibitors of HCV NS5B polymerase. Bioorg. Med. Chem. Lett. 2009, 19, 6404-6412. [CrossRef]

54. Tran, C.V.; Ruebsam, F.; Murphy, D.E.; Dragovich, P.; Zhou, Y.; Chen, L.; Kucera, D.; Blatter, F.; Viertelhaus, M. 5,6-Dihydro-1HPyridin-2-One Compounds. WO Patent WO2008124450A1, 16 October 2008.

55. Ghosh, A.K.; Bilcer, G.; Schiltz, G. Syntheses of FDA approved HIV protease inhibitors. Synthesis 2001, 43, 2203-2229. [CrossRef]

56. Crackett, P.; Demont, E.; Eatherton, A.; Frampton, C.S.; Gilbert, J.; Kahn, I.; Redshaw, S.; Watson, W. HIV protease inhibitor part 1: Use of Evans' oxazolidinone in intermolecular Diels-Alder reaction en route to 3,4-substituted cyclohexanones. Synlett 2004, 4, 679-683.

57. Evans, D.; Weber, A.E. Asymmetric Glycine Enolate Aldol Reaction. J. Am. Chem. Soc. 1986, 108, 6757-6761. [CrossRef]

58. Blanchette, M.A.; Choy, W.; Davis, J.T.; Essenfeld, A.P.; Masamune, S.; Roush, W.R.; Sakai, T. Horner-wadsworth-emmons reaction: Use of lithium chloride and an amine for base-sensitive compounds. Tetrahedron Lett. 1984, 25, 2183-2186. [CrossRef]

59. Ghosh, A.K.; Chapsal, B.D.; Weber, I.T.; Mitsuya, H. Design of HIV Protease Inhibitors Targeting Protein Backbone: An Effective Strategy for Combating Drug Resistance. Acc. Chem. Res. 2008, 41, 78-86. [CrossRef] [PubMed]

60. Ghosh, A.K.; Sridhar, P.R.; Leshchenko, S.; Hussain, A.K.; Li, J.; Kovalevsky, A.Y.; Walters, D.E.; Wedekind, J.; Grum-Tokars, V.; Das, D.; et al. Structure-Based Design of Novel HIV-1 Protease Inhibitors to Combat Drug Resistance. J. Med. Chem. 2006, 49, 5252-5261. [CrossRef] [PubMed] 
61. Sterrantino, G.; Zaccarelli, M.; Colao, G.; Baldanti, F.; Di Giambenedetto, S.; Carli, T.; Maggiolo, F.; Zazzi, M. Genotypic resistance profiles associated with virological failure to darunavir-containing regimens: A cross-sectional analysis. Infection 2012, 40, 311-318. [CrossRef] [PubMed]

62. De Meyer, S.; Lathouwers, E.; Dierynck, I.; De Paepe, E.; Van Baelen, B.; Vangeneugden, T.; Spinosa-Guzman, S.; Lefebvre, E.; Picchio, G.; De Bethune, M.P. Characterization of virologic failure patients on darunavir/ritonavir in treatment-experienced patients. AIDS 2009, 23, 1829-1840. [CrossRef] [PubMed]

63. Ghosh, A.K.; Kincaid, J.F.; Cho, W.; Walters, D.E.; Krishnan, K.; Hussain, K.A.; Koo, Y.; Cho, H.; Rudall, C.; Holland, L.; et al. Potent HIV Protease Inhibitors Incorporating High-Affinity P2-Ligands and (R)-(Hydroxyethylamino)sulfonamide Isostere. Bioorg. Med. Chem. Lett. 1998, 8, 687-690. [CrossRef]

64. Ghosh, A.K.; Dawson, Z.L.; Mitsuya, H. Darunavir, a conceptually new HIV-1 protease inhibitor for the treatment of drug-resistant HIV. Bioorg. Med. Chem. 2007, 15, 7576-7580. [CrossRef]

65. Sibi, M.P.; Matsunaga, H. Enantioselective Diels-Alder reactions of 3-(acyloxy)acrylates. Tetrahedron Lett. 2004, 45, 5925-5929. [CrossRef]

66. Kim, C.U.; Lew, W.; Williams, M.A.; Liu, H.; Zhang, L.; Swaminathan, S.; Bischofberger, N.; Chen, M.S.; Mendel, D.B.; Tai, C.Y.; et al. Influenza neuraminidase inhibitors possessing a novel hydrophobic interaction in the enzyme active site: Design, synthesis, and structural analysis of carbocyclic sialic acid analogues with potent anti-influenza activity. J. Am. Chem. Soc. 1997, 119, 681-690. [CrossRef]

67. Ishikawa, H.; Suzuki, T.; Hayashi, Y. High-Yielding Synthesis of the Anti-Influenza Neuramidase Inhibitor (-)-Oseltamivir by Three "One-Pot" Operations. Angew. Chem. 2009, 121, 1330-1333. [CrossRef]

68. Farina, V.; Brown, J.D. Tamiflu: The supply problem. Angew. Chem. Int. Ed. 2006, 45, 7330-7334. [CrossRef]

69. Hřebabecký, H.; Dračínský, M.; De Palma, A.M.; Neyts, J.; Holý, A. Synthesis of novel carbocyclic nucleoside analogues derived from 7-oxabicyclo[2.2.1] heptane-2-methanol. Collect. Czech. Chem. Commun. 2009, 74, 487-502. [CrossRef]

70. Gong, J.; Xu, W. Different Synthetic Strategies of Oseltamivir Phosphate: A Potent Influenza Neuraminidase Inhibitor. Curr. Med. Chem. 2008, 15, 3145-3159. [CrossRef]

71. Sagandira, C.R.; Mathe, F.M.; Guyo, U.; Watts, P. The evolution of Tamiflu synthesis, 20 years on: Advent of enabling technologies the last piece of the puzzle? Tetrahedron 2020, 76, 131440. [CrossRef]

72. Abrecht, S.; Harrington, P.; Iding, H.; Karpf, M.; Trussardi, R.; Wirz, B.; Zutter, U. The Synthetic Development of the Anti-Influenza Neuraminidase Inhibitor Oseltamivir Phosphate $\left(\right.$ Tamiflu $\left.^{\circledR}\right)$ : A Challenge for Synthesis \& Process Research. CHIMIA Int. J. Chem. 2004, 58, 621-629.

73. Shaim, H.; McCaffrey, P.; Trieu, J.A.; DeAnda, A.; Yates, S.G. Evaluating the effects of oseltamivir phosphate on platelet counts: A retrospective review. Platelets 2020, 31, 1080-1084. [CrossRef]

74. Yeung, Y.Y.; Hong, S.; Corey, E.J. A short enantioselective pathway for the synthesis of the anti-influenza neuramidase inhibitor oseltamivir from 1,3-butadiene and acrylic acid. J. Am. Chem. Soc. 2006, 128, 6310-6311. [CrossRef]

75. Satoh, N.; Akiba, T.; Yokoshima, S.; Fukuyama, T. Practical Synthesis of (-)-Oseltamivir. Angew. Chem. Int. Ed. 2007, 46, 5734-5736. [CrossRef]

76. Nakano, H.; Osone, K.; Takeshita, M.; Kwon, E.; Seki, C.; Matsuyama, H.; Takano, N.; Kohari, Y. A novel chiral oxazolidine organocatalyst for the synthesis of an oseltamivir intermediate using a highly enantioselective Diels-Alder reaction of 1,2dihydropyridine. Chem. Commun. 2010, 46, 4827-4829. [CrossRef]

77. Tsypysheva, I.; Koval'skaya, A.; Petrova, P.; Lobov, A.; Borisevich, S.; Tsypyshev, D.; Fedo-rova, V.; Gorbunova, E.; Galochkina, A.; Zarubaev, V. Diels-Alder adducts of 3-N-substituted derivatives of (-)-Cytisine as influenza A/H1N1 virus inhibitors; ste-reodifferentiation of antiviral properties and preliminary assessment of action mechanism. Tetrahedron 2019, 75, $2933-2943$. [CrossRef]

78. Sib, A.; Milzarek, T.M.; Herrmann, A.; Oubraham, L.; Meller, J.; Pichlmair, A.; Brack-Werner, R.; Gulder, T.A. Chemoenzymatic Total Synthesis of Sorbicatechol Structural Analogues and Evaluation of Their Antiviral Potential. ChemBioChem 2020, 21 , $492-495$. [CrossRef]

79. Naffziger, M.R.; Ashburn, B.O.; Perkins, J.R.; Carter, R.G. Diels-Alder Approach for the Construction of Halogenated, $o$-Nitro Biaryl Templates and Application to the Total Synthesis of the Anti-HIV Agent Siamenol. J. Org. Chem. 2007, 72, 9857-9865. [CrossRef] [PubMed]

80. Yamamoto, T.; Izumi, N.; Ui, H.; Sueki, A.; Masuma, R.; Nonaka, K.; Hirose, T.; Sunazuka, T.; Nagai, T.; Yamada, H.; et al. Wickerols A and B: Novel anti-influenza virus diterpenes produced by Trichoderma atroviride FKI-3849. Tetrahedron 2012, 68, 9267-9271. [CrossRef]

81. Kwong Jia Ye, D.; Richard, J.-A. Synthesis of the 6-6-6 tricyclic skeleton of the anti-influenza A diterpene wickerol A. Tetrahedron Lett. 2014, 55, 2183-2186. [CrossRef]

82. Liu, S.A.; Trauner, D. Asymmetric Synthesis of the Antiviral Diterpene Wickerol A. J. Am. Chem. Soc. 2017, 139, 9491-9494. [CrossRef]

83. Deng, J.; Ning, Y.; Tian, H.; Gui, J. Divergent Synthesis of Antiviral Diterpenes Wickerols A and B. J. Am. Chem. Soc. 2020, 142, 4690-4695. [CrossRef]

84. Adams, J.; Lepine-frenette, C.; Spero, D.M. Intramolecular Cyclopropanation-Ring Fragmentation Leading to Spirocyclic Ring Construction: A Stereoselective Synthesis. J. Org. Chem. 1991, 56, 4494-4498. [CrossRef] 
85. Inoue, M.; Carson, M.W.; Frontier, A.J.; Danishefsky, S.J. Total Synthesis and Determination of the Absolute Configuration of Frondosin B. J. Am. Chem. Soc. 2001, 123, 1878-1889. [CrossRef]

86. Maruoka, K.; Ooi, T.; Nagahara, S.; Yamamoto, H. Organoaluminum-catalyzed rearrangement of epoxides a facile route to the synthesis of optically active $\beta$-siloxy aldehydes. Tetrahedron 1991, 47, 6983-6998. [CrossRef]

87. Yang, Z.; Liao, H.; Sheng, K.; Chen, Y.; Yao, Z. Enantioselective Total Synthesis of Marine Diterpenoid Clavulactone. Angew. Chem. 2012, 124, 6590-6593. [CrossRef] 